\title{
Ficciones diaspóricas: identidad y participación en los blogs de tres desterradas venezolanas
}

\author{
Diasporic Fictions: Identity and Participation in Three \\ Blogs by Exiled Venezuelan Women \\ Ficções diaspóricas: identidade e participação nos \\ blogs de três exiladas venezuelanas
}

\section{Raquel Rivas Rojas}

Escritora y traductora independiente. Fue profesora titular del Departamento de Lengua y Literatura de la Universidad Simón Bolívar, Caracas, hasta septiembre de 2008. PhD en Estudios Culturales Latinoamericanos del King's College London (2001). Ha publicado: El patio del vecino (Equinoccio, 2013); Narrar en dictadura (El Perro y la Rana, 2011), y Bulla y buchiplumeo. Masificación cultural y recepción letrada en la Venezuela gomecista (La Nave Va, 2002). Vive actualmente en Edimburgo y mantiene dos blogs: Notas para Eliza y Cuentos de la caldera este.

\footnotetext{
Artículo de reflexión

Este artículo forma parte de un proyecto de investigación en curso sobre la literatura venezolana contemporánea. El proyecto dará como resultado un libro en el que se presentará un panorama de la literatura venezolana de los primeros tres lustros del siglo XXI, y abarcará géneros "menores", como el reportaje, la autoficción, el cuento y la novela policial. Documento accesible en línea desde la siguiente dirección: http://revistas.javeriana.edu.co
} 


\section{Resumen}

La narrativa del desarraigo se ha vuelto un lugar imposible de soslayar para la literatura venezolana contemporánea. A medida que la diáspora se expande, la noción de patria se modifica y amplía. Parte de esta reconstrucción discursiva sucede en textos que apuntan a un nuevo tipo de relato identitario en el que se elaboran distintas formas de arraigo en la comunidad global. A partir del estudio de textos de Mirtha Rivero, Liliana Lara y Leila Macor, en este artículo se explora el modo como algunas autoras venezolanas que viven en el exterior construyen la experiencia del desarraigo en blogs y portales electrónicos, y reformulan las nociones heredadas de pertenencia.

Palabras clave: diáspora venezolana, blogs, Mirtha Rivero, Liliana Lara, Leila Macor. Palabras descriptor:Diáspora venezolana, Rivero, Mirtha, 1956-, Lara, Liliana, 1966-, Macor, Leila, 1971- - blogs, autoras venezolanas, identidad nacional.

\section{Abstract}

The narrative of exile plays now a significant role in contemporary Venezuelan literature. As diaspora spreads the notion of homeland has been modified and extended. Part of this discursive reconstruction appears in texts that point to a new type of narrative of identity in which different forms of attachment to the global community are produced. Studying texts from Mirtha Rivero, Liliana Lara and Leila Macor, this article explores the ways in which some Venezuelan female writers living abroad construct the experience of uprooting sharing their thoughts in blogs and web portals, reformulating inherited notions of belonging.

Keywords: Venezuelan diaspora, blogs, Mirtha Rivero, Liliana Lara, Leila Macor. Keywords plus: Venezuelan Diaspora, Rivero, Mirtha, 1956 - Lara, Liliana, 1966 - Macor, Leila, 1971 - Blogs, women authors-Venezuelan, national identity.

\section{Resumo}

A narrativa do desarraigamento tem se tornado lugar impossível de desconhecer para a literatura venezuelana contemporânea. À medida que a diáspora expandese, a noção de pátria modificase e amplia-se. Parte desta reconstrução discursiva acontece em textos que apontam para um novo tipo de relato identitário no qual são elaboradas diferentes formas de enraizamento na comunidade global. A partir do estudo de textos de Mirtha Rivero, Liliana Lara e Leila Macor, neste artigo explora-se o jeito que algumas autoras venezuelanas morando no exterior, constroem a experiência do desarraigamento em blogs e portais eletrônicos e reformulam as noções herdadas de pertencia.

Palavras-chave: diáspora venezuelana, blogs, Mirtha Rivero, Liliana Lara, Leila Macor.

Palavras-chave descritores: Venezuelan Diaspora, Rivero, Mirtha, 1956 - Lara, Liliana, 1966 - Macor, Leila, 1971 Blogs, Venezuelan authors, national identity.

RECIBIDO: 16 DE MAYO DE 2013. EVALUADO: 7 DE JUNIO DE 2013. ACEPTADO: 7 DE JUNIO DE 2013.

\section{Cómo citar este artículo:}

Rivas Rojas, Raquel. "Ficciones diaspóricas: identidad y participación en los blogs de tres desterradas venezolanas". Cuadernos de Literatura 18.35 (2014): 226-246. 
LA NARRATIVA DEL desarraigo se ha vuelto en los últimos doce o trece años un lugar imposible de soslayar para la literatura venezolana contemporánea, debido a la creciente diáspora de jóvenes y profesionales que han salido del país en busca de un horizonte cultural y económico más amplio. A medida que la clase media se dispersa por los más variados destinos, la noción de patria se reformula. Esta reconstrucción discursiva circula, en gran medida, en textos que apuntan a un nuevo tipo de relato identitario elaborado a partir de distintas formas de pertenencia a la comunidad global. La relevancia de esta transformación se sostiene en dos aspectos que parecen cruciales a la hora de definir las fábulas de identidad de una comunidad no anclada en su territorio de origen. Se trata de los problemas del reconocimiento y la representación.

Frente a la política oficial empeñada en denigrar y excluir a los cientos de miles de desterrados que ha generado el régimen de $\mathrm{Chávez}^{1}$, se ha venido configurando una fuerte corriente discursiva que aspira a hacer visible la pertinencia y la beligerancia de esos venezolanos que quieren seguir ejerciendo sus derechos políticos y culturales desde el destierro. Porque estar afuera no debería privarlos de su capacidad de imaginar la nación y de redefinir sus rasgos, aunque se trate de un discurso a futuro, un discurso que se plantea una forma de regreso, incluso si solo se trata de una vuelta simbólica. Es por eso que los problemas de la representación cobran en este caso una crucial relevancia.

Todo texto que aspira a reconocer y a representar un grupo humano tiene forzosamente que lidiar con políticas de representación que pasan por una trama de cercanías y distancias, aceptaciones y rechazos cuyos efectos son difíciles de medir de manera concreta. Sin embargo, cuando se trata de hacer visible un grupo caracterizado por su ausencia física del territorio de la patria el problema se redobla. Sobre todo si de lo que se trata es de dibujar los contornos de una identidad disuelta o estallada que mira al mismo tiempo hacia el lugar de origen y hacia los posibles nuevos lugares de arraigo. Y esa es, precisamente, la tarea que

1 Un buen ejemplo de los efectos que ha producido esta política desintegradora puede rastrearse en la polémica que se desató a principios de mayo de 2012 sobre el video realizado por algunos estudiantes de la universidad Monteávila, llamado Caracas: ciudad de despedidas. La reacción ante este video puso en evidencia que la representación de los cada vez más numerosos desterrados venezolanos es un punto neurálgico para la opinión pública local. El hecho de que los realizadores del video -Ivanna Chávez Idrogo y Javier Pita- hayan sido insultados y amenazados por los medios oficialistas y sus seguidores dice mucho de la corriente de opinión que ha estado alimentando el sector gubernamental contra quienes han elegido la opción del destierro. 
están asumiendo los textos de algunos de los intelectuales venezolanos que viven en situación de destierro².

Aunque se trata de un tema que recorre los más diversos medios y géneros, desde novelas y cuentos, pasando por videos semidocumentales hasta llegar a las páginas de ayuda para salir del país, mi intención es explorar aquí, particularmente, el modo como algunas autoras venezolanas que viven en el exterior construyen la experiencia del desarraigo en blogs y portales electrónicos. Quisiera centrarme específicamente en tres a quienes considero representativas de un modo particular de construir relatos del destierro con punto de arraigo en la tradición venezolana: los textos de Mirtha Rivero, que hasta el 28 de marzo de 2012 aparecieron en el portal Prodavinci, luego de ser publicados en el suplemento dominical Día D del diario caraqueño 2001; el blog de Liliana Lara, Memorias de la mamacita; y los textos de Leila Macor, que aparecen tanto en su blog personal, Escribir para qué, como en el portal Observa Ciudadano, manejado por el periódico uruguayo El Observador.

Las crónicas que circulan por la web, sea en portales electrónicos o en el formato blog, permiten observar una práctica discursiva que, al elaborarse desde la cercanía de la bitácora, del registro cotidiano, produce una imagen menos decantada que la que puede leerse en textos literarios. Pero al mismo tiempo más cercana al proceso de fabricar presente, como denomina Josefina Ludmer a la función central de las literaturas posautónomas. Según Ludmer, las escrituras postautónomas que circulan hoy en día forman parte la imaginación pública que se define como "un trabajo social, anónimo y colectivo de construcción de realidad". Se trata de textos que contribuyen a la creación de un lugar público en el que "se borra la separación entre el imaginario individual y el social" y, sin embargo, es al mismo tiempo "lo que está afuera y adentro, como íntimopúblico". De este modo, según Ludmer, gran parte de los textos que leemos hoy en día transitan por el terreno de la "realidadficción" y desde ahí producen relatos identitarios cuyo referente se asienta en tradiciones textuales híbridas (Aquí 11).

2 Considerar la emigración como destierro o exilio enmarca la experiencia de la migración en un paréntesis entre dos viajes. El regreso definiría el final del destierro y convertiría la experiencia del desarraigo en un estado pasajero. Dado que la razón por la que tantos venezolanos han estado emigrando en los últimos años está claramente vinculada a la situación política del país, no me parece descabellado afirmar que un gran porcentaje de esos migrantes mantiene en su horizonte de expectativas la posibilidad de volver "cuando las cosas mejoren". Pero la realidad del destierro no siempre responde a esa esperanza. Es por eso que la elección de los términos -exilio, destierro- se inscribe aquí en una política de los afectos, de las esperanzas y las expectativas y no, necesariamente, en una definición jurídica. Para una definición de los distintos términos véanse Said; Pavel. 
Se trata de una mezcla de periodismo con diario íntimo, crónica con poesía, especulación ensayística con ficción histórica.

Esta amalgama de textos híbridos sirve de base para la elaboración de un presente en el que aparece con insistencia el relato de la nación desmembrada, jalonada por los impulsos centrífugos de la globalización. Porque, aunque se ha insistido en que estos formatos cumplen la función central de producir autoficciones, de poner en escena el solipsista espectáculo del yo (Sibila 265), no es posible pasar por alto el hecho de que en las autoficciones de los sujetos desterrados los relatos de identidad nacional tienen todavía un peso específico. Esto se debe a que una de las tradiciones más persistentes en la cultura latinoamericana en general -y muy en particular de la venezolana- ha sido, precisamente, la que se somete al imperativo decimonónico de construcción de la nación ${ }^{3}$.

Según esta tradición, nacida con las repúblicas que se independizaban de España a principios del siglo XIX, todo intelectual debía responder a una demanda de representación de las naciones emergentes. Las repúblicas no solo se fundaron con la espada en los campos de batalla. Debían ser también elaboradas discursivamente. Y ese discurso, que formuló desde las leyes hasta las novelas fundacionales, inauguró una tradición que se sostiene hasta hoy ${ }^{4}$. De ahí que, incluso en géneros tan centrados en la ficcionalización del yo -como las bitácoras, los diarios íntimos, las cartas, las crónicas de lo cotidiano-, siga estando presente la tendencia a producir o reproducir fábulas de identidad nacional.

Construir un discurso de reconocimiento, que genere una marca al mismo tiempo local -el acento venezolano- y global -donde quiera que esté-, parece ser al menos una de las tareas abordadas en algunas de estas bitácoras del destierro. En ellas se despliega un modo de mirar, un horizonte cultural, un archivo de referencias, que configura una forma muy particular de estar en situación de destierro, que no es equivalente -por poner solo un ejemplo- a los modos argentinos, mexicanos o chilenos de ser desterrados. Y, por esa vía, estas fábulas de identidades

3 Son innumerables los textos que trabajan con los distintos proyectos de construcción de las naciones latinoamericanas y que muestran que el afán por definir los rasgos nacionales no solo abarca las primeras décadas posteriores a la Independencia, sino que se expande y prolifera a lo largo del siglo XIX, e incluso se mantiene como problema vigente hasta principios del siglo $\mathrm{XX}$. Está fuera del alcance de este texto mencionar toda la bibliografía referente al tema, pero, solo como punto de referencia, véase la compilación de González et al.

4 Con respecto a América Latina en general, véanse Rama; González Echevarría. En lo que se refiere al caso venezolano, véase el artículo de Paulette Silva Beauregard, en el que analiza la reactivación o persistencia de la relación ficción-nación en la narrativa venezolana contemporánea. 
desarraigadas van reconfigurando una idea de nación que funciona a contrapelo de la tradición arraigadora, aunque esté en diálogo permanente con ella.

De manera particular, las mujeres venezolanas que escriben desde el destierro producen un énfasis en lo íntimo que sirve de contrapeso a esa tradición establecida sobre un discurso androcéntrico, para el cual la nación es una empresa excluyente, una hermandad masculina. En los textos de estas mujeres que escriben fuera de los límites geográficos de su lugar de origen la representación se construye desde el afecto y la cotidianidad. La pertenencia no es una práctica que deba ser aceptada a la fuerza sino un discurso construido desde la memoria familiar, los relatos íntimos, los chismes y los chistes, las afinidades sentimentales, las anécdotas pequeñas, la reconstrucción minuciosa de los malentendidos y el sinfín de errores que comete todo desterrado en ese paréntesis que se abre durante el exilio y que nunca se sabe si podrá ser cerrado alguna vez ${ }^{5}$.

La nación, en estos textos posliterarios que están armando un mapa del destierro venezolano, puede ser reconstruida en una memoria selectiva, que convenientemente olvida o reformula un pasado fragmentario. El lugar de origen no requiere lealtades absolutas, porque es un resto que puede evocarse a voluntad, una ruina que puede dejarse en el olvido, como se deja abandonado un equipaje innecesario a la orilla del camino. Pero también es posible insistir en evocar un pasado común para establecer el contraste entre el antes y el ahora, para construirse un lugar en el mundo en el que el origen tenga un peso específico pero no determinante y el derecho a opinar, a reclamar, a participar en el horizonte cultural de la nación no sea confiscado por la distancia. Porque en estos textos no se renuncia al derecho a intervenir en el debate venezolano. Pero esta participación se emite, no desde un horizonte local, sino desde la pertenencia a un espacio-mundo que ofrece una perspectiva única para entender la patria del presente e imaginar la nación futura.

\section{En suelo prestado}

Este es el afán que alimenta los textos de Mirtha Rivero que aparecieron en el portal Prodavinci entre el 2 de noviembre de 2010 y el 28 de marzo de 2012, después de su publicación impresa en el suplemento dominical del diario 2001. En estos escritos, la periodista venezolana residenciada en Monterrey establece un continuo diálogo con el acontecer venezolano visto desde su casa, sus hábitos cotidianos, las

5 En este sentido, los blogs estudiados aquí continúan una tradición que Josefina Ludmer ha caracterizado como las tretas del débil, para acentuar el carácter cotidiano de las representaciones debido a la clara inmediatez del formato. 
conversaciones con amigos y familiares, los viajes de ida y vuelta, las lecturas y los recuerdos. Se trata de crónicas en las que la necesidad de comentar y valorar lo que sucede en el lugar de origen está siempre presente, pero recortada sobre el marco del destierro, de la distancia que le da un matiz distinto a la voz que enuncia.

La primera característica de esta voz es una itinerancia constante. Los textos se escriben en Monterrey y se publican en Caracas, antes de aparecer en formato digital. Esto produce un doble foco a partir del cual se le habla a una audiencia de compatriotas desde un lugar geográfico distante. La distancia produce, así, un modo de ver que enfatiza las claras diferencias entre los problemas que se viven dentro -escasez, inseguridad, desempleo, inflación galopante, incertidumbre jurídica y un largo etcétera- $\mathrm{y}$ la vida de abundancia y sosiego que es posible construir afuera, no sin que aparezca un sentimiento de culpa. Este contraste puede apreciarse en el texto llamado "Aterrizaje":

Martes, ocho de la noche: salgo de Monterrey rumbo a Caracas, con escala en Ciudad de México. Las maletas -repletas- se pasaron por kilo y medio. Mi marido me ve condescendiente. Atrás quedaron sus quejas (¿iy qué tanto llevas? preguntaba mientras yo trataba de meter en cualquier hueco libre un $\mathrm{CD}$, un libro, una bolsa de dulces, un rebozo, un paquete de comida especial para gatos...). Cincuenta y un kilos y medio marca la pesa, y respiro aliviada. No importa -como ya caí en cuenta- que se me hayan quedado la correa, las sandalias negras y viaje con solo seis pantalones para doce días. Sonrío pensando que no conozco Cuba, pero cada vez que voy a Venezuela, rememoro las peripecias de amigas que, ya en los años setenta, viajaban a la isla de la felicidad cargando hasta con trenzas para zapatos y cuerdas de guitarra. La historia se repite, me digo, aunque en otro país (el mío). (22 de febrero de 2011)

El contraste entre la relativa abundancia del país de acogida y la asombrosa escasez que se vive en el lugar de origen -que debería ser un país rico y que hasta hace nada lo fue- reaparece una y otra vez en las crónicas de Mirtha Rivero. Porque sus vínculos con Venezuela se mantienen y su destierro se construye en un permanente viaje de ida y vuelta. Es por eso que las interrogantes sobre el bienestar se vuelven una pregunta identitaria que regresa una y otra vez, como sucede en el texto en el que Rivero comenta una serie de encuestas realizadas en distintos países del mundo, que ubican a Venezuela entre los pueblos más "felices" del planeta. Sin entrar a discutir la validez del instrumento por el cual se mide la supuesta felicidad, en este texto titulado "Infeliz", la autora reflexiona en primera persona del plural: 
Así que no hay tutía: somos, nos sentimos o nos creemos de los seres más happies del universo.

Puedo imaginar la sonrisa de los encuestados a la hora de enfrentarse a los encuestadores. Lo que no me termina de caber en la cabeza es la manera en que -según tan distintas fuentes- somos capaces de mentir de un modo tan descarado.

¿O será que hemos llegado a un estado tal, que la gente es feliz simplemente porque puede respirar? Porque se bandea con la inflación y la escasez. Porque la delincuencia no lo ha tallado (que levante la mano quien no la ha visto de cerca). $\mathrm{O}$ porque el cachazo que nos propinaron al robarnos -gracias a Dios- no nos dejó gafos. O porque se metieron en la casa y se llevaron hasta la alcancía del hijo más pequeño, pero "no nos hicieron daño".

Entiendo que, en Venezuela, alguien -cualquiera- se sienta aliviado si tiene trabajo, y no lo orillan estrecheces ni el hampa ha tocado a su puerta. Pero ¿y qué pasa con el que vive al lado? ¿Acaso no afecta lo que le sucede al hermano, al primo, al amigo o al vecino de la esquina? ¿Cómo se puede ser feliz cuando la miseria, el miedo y el horror se instalan en la cuadra, en la ciudad, en el país entero? (10 de febrero de 2012)

El contraste no podría ser mayor entre la supuesta felicidad registrada en las encuestas y la escasez y el desencanto que aparecen en otras crónicas, en las que el país de origen se presenta como un lugar abismado en su propia miseria y en su propio terror. Pero lo que me interesa de este fragmento es la construcción de una primera persona del plural en la que la cronista se incluye. A pesar del destierro, ese nosotros sigue marcando una posición enunciativa que da cuenta del deseo de pertenecer que no se mitiga con la distancia. Porque el desterrado no renuncia a su derecho a producir relatos identitarios, casi siempre elaborados a contrapelo del discurso oficial, dibujados a partir de la duda y la angustia, pero también desde retazos de nostalgia. Una nostalgia que Boym llamaría reflexiva, porque no se queda en la contemplación del pasado ni se contenta con la restauración de los símbolos de una comunidad nacional, sino que pone en primer plano la memoria individual -una forma de "intimidad cultural" - que se detiene en los detalles, que atesora fragmentos y puede hacer uso del humor $y$ la ironía $(42,49)$.

Es por eso que a la hora de aceptar el nuevo arraigo se recurre a la memoria y a los contrapesos que hacen más llevadera una distancia que parece crecer día a día. Así se hace evidente en uno de los últimos textos publicados por Mirtha Rivero en el portal Prodavinci, titulado "En suelo prestado". Allí, la cronista 
comenta que, después de vivir seis años en una casa alquilada, se muda a una casa propia y esa nueva forma de arraigo le produce sentimientos encontrados:

Me he mudado varias veces en mi vida, vuelvo a decirme... Pero nunca antes me había tocado hacerlo en un país que no es el mío.

Desde que mi marido y yo llegamos a México, rentamos una casa pequeña en las faldas de una montaña. Es una construcción hermosa y acogedora -una casa prestada, siempre he dicho-adonde un día llegó, para quedarse, una gata mestiza. Ahora, después de seis años de vivir en este suelo -un suelo prestado-, tomamos la decisión de cambiarnos. La nueva casa también es hermosa, también es en la misma ciudad y está al pie de una montaña. Pero ya no será una casa alquilada.

Comprar una propiedad simboliza posesión, pero comprar una propiedad para habitarla (no para vacacionar; no por invertir) más que dominio, significa establecerse. Apunta al largo plazo. Comprar una casa para vivir en un país que no es el de uno insinúa el arraigo. Y también un desarraigo. ( $1 .^{\circ}$ de marzo de 2012)

De lo que se trata es de hacer evidente esa situación emocional siempre precaria en la que se encuentra el sujeto en destierro. Un sujeto para el que el nuevo arraigo ensancha las distancias y produce nuevas nostalgias. Pero no hay demasiado tiempo para la queja. La solución está al alcance de la mano, y apela a una identidad que se fragua en lo íntimo, en la cocina, en los sabores y olores desde los que se puede recobrar un sentido del terruño:

Acabo de desayunar, pero en este instante se me antoja una comida como la de mi casa. La propia, la de antes, la de siempre. Y eso será nuestro almuerzo dominguero. Lo acabo de decidir: ahora mismo salgo para el supermercado, porque hoy comeremos arepas (sí, aquí sí se consigue Harina Pan, aunque hecha en Colombia) con jamón, queso, caraotas refritas (a Dios gracias, por todos lados las venden hechas), plátano frito y aguacate.

Evocando a mis sabores -los que me dicen de dónde vengo, de dónde soyme preparo para la vida en una nueva casa. (1. ${ }^{\circ}$ de marzo de 2012)

Las comidas distintivas aparecen en estas y otras crónicas de desterradas como una marca identitaria que reconstruye las ficciones de arraigo en una clave menor, lejos del discurso grandilocuente que habla de héroes históricos o figuras destacadas del presente. La identidad dentro de la casa, propia o prestada, se teje entre la memoria y la vida cotidiana. Y desde allí se recrea una manera particular no solo de ser exiliada, sino de concebir la propia identidad. Lo 
íntimo y lo público confluyen en estos textos en los que no solo se produce el espectáculo del yo, sino también -y sobre todo- se pone en escena el dilema de la pertenencia. En esta reconfiguración de la idea de nación más allá de los límites geográficos, el sujeto identitario encuentra un lugar adecuado en el cual habitar: el lenguaje. Pero no se trata de un lugar estable, porque el desterrado habita con frecuencia entre lenguas. Y en ese lugar híbrido su reconfiguración identitaria tiene un acento vernáculo.

\section{Sufrir el acento}

El blog de Leila Macor ofrece un énfasis particular en el tema del reconocimiento de la identidad a través del acento, porque se trata de una venezolana que ha vivido un doble desplazamiento -hacia Uruguay, primero, y luego a Los Ángeles-, y su experiencia de estar entre culturas tan diversas le ha permitido elaborar una reflexión sobre los modos de hablar la misma lengua -el acento venezolano escuchado por los uruguayos- y las distintas identidades que producen los acentos de los latinos que hablan en inglés en los Estados Unidos. En sus textos, marcados por el estilo de la crónica periodística, no es necesario cambiar de idioma para sufrir los típicos malentendidos a los que se ve sometido todo migrante. Abundan entradas en las que aparecen escenas como esta:

-Disculpe que no cerré los sobres, pero no tenía pega en mi casa, ¿no me darías un poco? -le pregunté a la encargada de la oficina de correos. Siempre mezclo el tuteo con el usteo. No sé hablar con un solo protocolo.

- ¿Que si tengo un poco de qué cosa? -me preguntó la mujer.

-De pega.

-¿Qué es "pega"?

-Pega, pega. Para pegar cosas. Cerrar sobres. Hacer que las cosas se peguen. -¡Ah! Goma de pegar.

La miré con expresión de vaca con tránsito lento. (6 de agosto de 2010)

Un mismo idioma puede ser motivo de complicadas escenas absurdas en las que está en juego no solo la comprensión de lo que se dice, sino también la imagen que se tiene de la nacionalidad. En este mismo texto, que se titula "El precio de las dedicatorias", la narradora tiene que ir a una tienda a comprar la "goma de pegar" que no ha conseguido en la oficina de correos y, por andar descuidada pensando en la entrada de blog que va a escribir con lo que le está pasando, sale de la tienda con la barra de pega en la mano y solo un rato después se da cuenta de que no la ha pagado. Entonces se pregunta qué hacer, y aunque su primera reacción es devolverse a la tienda a pagar, al imaginarse la escena inverosímil 
-"Llega una tipa con acento venezolano [...] pidiendo disculpas y rogando que por favor le cobren esa barrita que se acababa de llevar sin querer porque estaba distraída escribiendo mentalmente [...]"- decide otra cosa:

Cuando uno tiene acento venezolano, debe asumir algunas realidades. Una de ellas es que nadie te cree que no hayas tenido la intención de robar. A uno mismo le cuesta creérselo. El venezolano es ladrón por definición. El robo no solo es socialmente aceptado, sino socialmente aplaudido. Es símbolo de hombría, de viveza. Y, por el contrario, los uruguayos son gente seria, para los que robar es algo que está MUY MAL. Un uruguayo promedio no robó jamás un durazno de una verdulería. Yo en cambio tenía "mejores amigos" que me robaban constantemente en mi casa -y tampoco estoy libre de pecado-. O sea que robarle a un uruguayo una barrita de pega, con mi acento venezolano, era algo que estaba lleno de vergonzosas implicaciones psicosociales para mí. Era como hacerle trampa a un niño en ajedrez. (6 de agosto de 2010)

La marca del acento, con sus "vergonzosas implicaciones psicosociales", define este sujeto que sin embargo trata de escapar del "pecado" ejerciendo una buena acción y regalando más adelante la barra de pega, pero sin ser notada:

No porque realmente quisiera hacer una donación anónima, sino porque ella iba a interpretar el regalo como una ironía petulante de mi parte. Y no podía explicarle que no lo era, sino que [...] me había robado la barrita sin querer y que como soy venezolana no me atrevía a devolverla y que por eso había decidido darle un fin noble. Estoy al tanto de que mi lógica puede dejar atónita a la gente que atiende los comercios. Así que anonimato. Más noble, imposible. Los venezolanos solemos robar recursos al Estado. Pero que un venezolano regale anónimamente recursos al Estado de otro país sin pedir apoyo político a cambio, ja! Eso sí que no lo había escuchado jamás. (6 de agosto de 2010)

El modo como el Estado-nación imprime en sus ciudadanos una marca identitaria negativa se ve aquí caricaturizado. Pero se trata de una exageración que produce el efecto de mostrar las desventajas de la pertenencia. Ser venezolano no es aquí una virtud, sino un estigma que la narradora tiene que sortear con algo de ingenio y buena fe. Lo que cuenta, sin embargo, en este relato identitario, es el modo como el desterrado se escabulle de la marca identitaria que se le asigna a través de una acción anónima. Pero, aunque el anonimato se vuelve la solución al dilema identitario en el que se encuentra esta desterrada venezolana, en su tono no hay asomo de queja ni aparece ninguna diatriba contra 
los males de la nacionalidad que le ha tocado en suerte. En las crónicas de Leila Macor la identidad produce malentendidos, pero no amarguras.

Cuando Macor comienza a vivir en Los Ángeles y contrata a una instructora que la ayude a perfeccionar su inglés, las tribulaciones identitarias marcadas por el acento volverán a aparecer en el mismo tono humorístico. En el post titulado "Stop Being Sweet" la marca identitaria reflejada en el acento se convierte en una clara desventaja que es necesario superar con una performance, con una impostura identitaria:

"You sound too sweet". /"Of course I sound sweet, I AM sweet".

"Well, stop being sweet!". /Así de simple. Que deje de ser dulce. Sencillísimo. De golpe esa supuesta dulzura de la que he sido acusada toda mi vida, y que cuando vivía en Uruguay me era además muy útil para ganar simpatías, se convierte en un defecto del que debo deshacerme. Como si fuera una sábana sucia, un cepillo de dientes olvidado por un visitante que tal vez no vuelva.

"It makes you sound insecure", me dice mi profesora de pronunciación. Lo primero que me enseñó es que la única forma de pronunciar bien el inglés es mostrando mucha confianza en mí misma. "Pero si no tengo", le explico. "Fake it", me ordena. "Fake it until you make it", me dice, repitiendo una expresión típicamente estadounidense que lo resume todo. (21 de octubre de 2011)

Fingir se vuelve entonces la solución al dilema identitario de quien resulta demasiado dulce en un ambiente en el que la fachada de la seguridad es primordial y debe ser actuada, representada, hasta que se obtenga el efecto deseado: "Porque la proyección, la autopromoción y la confianza están en las bases del ser estadounidense". Y de lo que se trata es de destacar en un medio lleno de prejuicios en el que el origen latinoamericano produce una marca identitaria automática: "Cuando les digo que trabajo para la agencia francesa de noticias, me preguntan si soy francesa. He notado cambios de actitud muy sutiles si les aclaro que no, que soy venezolana. De golpe ya no les sueno como una romántica europea, sino como la mujer que les cuida los niños" (21 de octubre de 2011).

En esta situación, el sujeto que busca un reconocimiento debe construirse una identidad performativa que le permita hacerse entender y, sobre todo, lograr una aceptación no marcada por el prejuicio. Pero esta puesta en escena del acento produce un efecto complejo, un cambio drástico de personalidad:

Hice los deberes y tuve un par de conversaciones totalmente fingidas para mí: abrí muchísimo la boca y dije las frases despacio, exagerando los movimientos. Como Doris, la novia del papá de Nemo, cuando se pone a hablar en 
ballenés. Como si me doliera la mandíbula, con un aparente convencimiento interno que me parecía de una vergonzosa ausencia de sentido del ridículo. Y funcionó. Me entendieron.

Al parecer, la dulzura, la venezolanidad y el sentido del ridículo no son aptos para la supervivencia./La buena noticia es que la solución es muy simple: solo tengo que cambiar los pilares que cimientan mi personalidad. Haberlo dicho antes. Sencillísimo. (21 de octubre de 2011)

El profundo cambio que implica fingir lo que no se es, hablar como si no se tuviera el más mínimo "sentido del ridículo" y como si el origen no contara, parece mostrar aquí uno de los límites a los que se ve empujado el sujeto que migra con aspiraciones de ser aceptado como un igual en el espacio de acogida. La identidad particular, sobre todo los rasgos que se relacionan con los modos de hablar, la gestualidad y las actitudes frente a los otros, debe amoldarse. Y en ese proceso la representación, la puesta en escena, juega un papel central. Esta idea se reitera en la entrada titulada "El instrumento de la alegría", en la que la narradora cuenta cómo ha intentado llevar a la práctica las conclusiones de un experimento alemán según el cual las expresiones faciales no son solo producto de un estado de ánimo, sino que pueden ser su causa.

Este experimento concluye que la risa fingida, producida por el acto de mantener entre los dientes un lápiz que obligue a activar los músculos con los que se sonríe, produce un auténtico sentimiento de regocijo. Siguiendo esta lógica, la narradora sostiene por media hora una sonrisa fingida antes de asistir a una cena a la que no tiene ganas de ir. Pero la experiencia resulta fallida:

Pero no llegué contenta a la cita, tal vez porque conocía el objetivo de mi experimento. Paradójicamente, la falsedad tiene que ser espontánea o no funciona. Quizá me aparezca con un lápiz entre los dientes la próxima vez. "Estoy enviando mensajes positivos a mi cerebro", explicaré. "Me estoy adaptando al American Way of Life. No se preocupen por el lápiz. Es solo el instrumento de mi alegría". (20 de diciembre de 2011)

La espontaneidad y el fingimiento, lo auténtico y lo falso, se cruzan en este blog en el que Leila Macor intenta explorar los límites de una identidad profundamente escindida, producto de un doble destierro. Sus soluciones no parecen permanentes, pero producen un efecto humorístico que está muy lejos de la tradición dramática de la literatura del destierro. Las quejas se vuelven aquí acciones disparatadas y el deseo de pertenecer no anula una mirada crítica y profundamente irónica frente a la cultura a la que será preciso asimilarse. 
Esta distancia crítica es la base sobre la que se construyen las escenas de desencuentros y malentendidos que ponen sobre el tapete un modo de experimentar el destierro que habilita un lugar beligerante para el sujeto que construye un relato identitario flexible, alejado de las restricciones arraigadoras de la nacionalidad. Es precisamente ese posicionamiento descentrado el que le permite a Leila Macor hacer comentarios sobre la situación venezolana sin los compromisos adquiridos de quienes deben lidiar con el día a día de la política local. Tal vez por eso, a la hora de elegir un tema político, opta por un comentario ligero sobre los poderes histriónicos del presidente Chávez:

Semanalmente el presidente venezolano da rienda suelta a su fluir psíquico, para fascinación de su público revolucionario y exasperación de los periodistas que deben escarbar una noticia oculta entre una anécdota de la abuela y la receta de la sopa de calamares de ayer. Y un video registra el programa en el que, en medio de su pertinaz verborrea, Hugo Chávez recuerda el día aquel en que tenía que inaugurar un túnel, pero "andaba con un cólico"... El errático discurso político del jefe de Estado se detiene y comienza la perfecta narración de una historia personal. Tenía retorcijones en la panza, sudaba frío y necesitaba ir al baño urgentemente, pero la prensa, los pobladores del lugar, los funcionarios de gobierno y la propia solemnidad del acto le impedían correr al baño apretando las nalgas como hubiera querido... “¡Ay Dios mío, ten piedad de mí!", exclama el presidente, que parece un profesional del "stand up comedy": estupenda administración del suspenso a través de nudos discursivos, gran histrionismo y sobre todo un impecable manejo del humor popular... Chávez habría sido un excelente humorista. Qué lástima que le dio por otro lado. Qué desperdicio de talento. (1. ${ }^{\circ}$ de diciembre de 2008)

El comentario político se sale aquí de las lógicas binarias del debate local. La autora reconoce las virtudes discursivas del presidente Chávez y la fascinación que causa entre su público. Un reconocimiento que por el reverso niega las virtudes políticas del mandatario, pero que se expresa de manera oblicua, sin recurrir al insulto o la descalificación, que se han vuelto lugar común en el debate local. Del mismo modo, el análisis político puede aparecer de manera oblicua en el comentario sobre la actividad de otra bloguera, cubana y muy conocida: Yoani Sánchez.

Yoani es la sociedad civil, manifestándose con mucho ruido en el silencioso Internet, que se expande con la peligrosa rapidez de una progresión geométrica. Y el Gobierno, impotente, se ha encontrado con que silenciar a un bloguero es tan difícil como contener agua en un puño. Un régimen autoritario 
puede censurar o imponer el contenido de un diario o de un canal pero no puede controlar el contenido de la web, que carece de una organización jerárquica pasible de recibir y acatar órdenes. Así que debió actuar el propio Fidel Castro. Hace poco acusó a Yoani de humillarse ante la "prensa neocolonial de la antigua metrópoli española" por aceptar aquel premio [el Ortega y Gasset al periodismo digital del 2008], uno de los tantos "que propicia el imperialismo para mover las aguas de su molino".

Él mismo tuvo que haberse reído después de escribir eso. (13 de julio de 2008)

A través de comentarios como este, Leila Macor ejerce su derecho a poner a circular sus opiniones sobre la política regional desde un lugar que apela a la capacidad expansiva y beligerante del mismo medio en el que se expresa, y lo opone a las tendencias totalitarias de un sistema político que está en estrecha relación de contigüidad con el régimen venezolano, y que al igual que este ha querido por años "controlar el contenido de la web". De este modo, al hacer referencia al trabajo de una colega que vive bajo un régimen opresivo, Macor construye la idea de una comunidad simbólica que funciona en un espacio sin fronteras y mantiene un diálogo que va más allá de las nacionalidades y que se reconoce, sobre todo, en el idioma. Un idioma común capaz de superar la barrera de los acentos.

\section{Habitar el abecedario}

Este es también, en cierto modo, el empeño que sostiene Liliana Lara en las últimas entradas de su blog, en las que ha estado construyendo un Abecedario del estío que recorre, de la $A$ a la $Z$, un territorio en el que se confunde el paisaje israelí en el que vive con el origen maturinés que atesora en la memoria, y todas las posibilidades identitarias de vivir en una encrucijada cultural ${ }^{6}$. Por este abecedario transitan las dichas y los miedos, los conformismos y las rebeldías de quien se adapta y se pliega a la nueva cultura; al tiempo que retrocede a veces para establecer una distancia crítica y hacer balance y cuenta nueva.

Es así como en la "C de cuentos" irrumpe en la vida cotidiana un mapa de Maturín que el marido pega en la pared y desata, en principio, una disputa familiar:

6 Liliana Lara comenzó a publicar el Abecedario del estío el lunes 19 de septiembre de 2011, siguiendo la inspiración que le otorgaron dos libros en los que se hace un ejercicio similar: el abecedario del poeta polaco Czesław Miłosz y el ABC del escritor israelí de origen polaco Dan Tsalka, inspirado a su vez en el texto de Miłosz. El 25 de septiembre Liliana publicó la última entrada, "Z de zapatos" en su blog. El 27 de noviembre anunció que retiraba del blog todas las entradas del Abecedario para "convertirlas en otra cosa". 
A ningún venezolano -le dije- se le ocurriría la estrafalaria idea de poner un mapa de Maturín en la pared de la cocina. Que él no era venezolano -me dijo- y que había pensado que ya que soy maturinesa me gustaría ver ese mapa. Pobre - pensé moviendo la cabeza reprobatoriamente - ¡en verdad que es extranjero! (20 de septiembre de 2011)

Pero el mapa se instala en la rutina cotidiana y comienza a despertar recuerdos, historias, relatos contados por la madre o el padre, imágenes vistas o leídas, colores y sonidos. El mapa no solo evoca el territorio de origen sino que también despierta en la autora un deseo de contar, de recrear ficcionalmente un territorio que pertenece más al terreno de la imaginación que al de la realidad. Y ese impulso produce una revelación que se muerde la cola:

A veces escribo para recordar lugares, personas, cuentos que me contaron y que se quedaron en mi cabeza por años.

Aunque mis cuentos no son autobiográficos, a veces escribo para recordar quién fui y de dónde era. /Tuve que agradecerle a D. ese mapa que ningún maturinés pondría jamás en su cocina. ¡En verdad que yo misma soy tan extranjera! (20 de septiembre de 2011)

La irrupción del mapa genera aquí un contraste entre la realidad del presente y los juegos de la memoria, y dispara una producción textual que muestra el carácter ficcional de toda pertenencia, porque el lugar de origen no es otra cosa que una acumulación de historias escuchadas o reinventadas. Y esa memoria fragmentaria no ofrece un terreno más firme de arraigo que el lugar de llegada en el que el inmigrante se instala. Por eso la pertenencia se va construyendo entre la memoria y la vida cotidiana, y gira en torno a afinidades discursivas y afectivas, como puede leerse en las entradas dedicadas a escritores y lecturas ("J de judías"; "M de Miłosz"; V de "Véase amor", entre otras).

Ese espacio simbólico por el que transita la reconfiguración de la identidad del desterrado aparece una y otra vez en el Abecedario del estío, como una marca que al mismo tiempo limita y libera al sujeto que se reconfigura en una nueva clave identitaria. Esto se hace evidente en escenas de reconocimiento o interpelación como la que aparece en "Q de quién":

${ }_{-}{ }_{\mathrm{C}}$ Cuál es su nombre? -me pregunta el empleado-.

Me quedo callada sopesando la respuesta. Pasan por mi cabeza todas las posibilidades de mis nombres: reales, legales, imaginarias, artísticas, locales, extranjeras. Y como no respondo inmediatamente el empleado me ve con mala cara. Creerá que soy tonta, autista, sospechosa, ladrona, tramposa. Veo 
barajarse todas las posibilidades de mi condición ante sus ojos, así como se barajan en mi cabeza todas las posibilidades de mi nombre./Las posibilidades de mi nombre son infinitas -pienso y me causa mucha gracia-. Me regocijo con mi pluralidad antes de contestar alguna de las combinaciones posibles./ -Norma Singer -respondo finalmente-". (17 de octubre de 2011)

Esta escena de interpelación en la que el nombre propio, lo que más claramente distingue a un sujeto de otro, puede ser elegido a voluntad a partir de un repertorio variado, ofrece una de las claves de lectura de los textos del desarraigo venezolano que circulan en la web. El tema de la desintegración del sujeto que elige -conscientemente- no reintegrarse, sino mantener la dispersión y reconfigurar su imagen alrededor de una serie de disfraces alternativos y no de una versión única es lo que reitera Liliana Lara -o Norma Singer- en la entrada que se titula "M de Miłosz", al dar cuenta de su deuda con Miłosz y Tsalka en la elección del abecedario como género para la autoficción:

Miłlosz armó su autobiografía a manera de un abecedario. Tsalka -quien también era polaco, pero tomó rumbo al Levante apenas pudo- dice que abecedarios, diccionarios y enciclopedias hay muchos, sin embargo la innovación de Miłosz fue darle a su abecedario un carácter autobiográfico y a la vez no hablar directamente de sí mismo sino a través de los otros. Tsalka tomó la idea para sí. Ambos hablaron sobre sí mismos a través de los otros, a través del orden de las letras, uno con el alfabeto polaco, otro con el alfabeto hebreo. Me doy ánimos a mí misma pensando que mi mayor innovación en el género alfabético será la presencia de la letra eñe, aunque en realidad todavía no tengo idea de la palabra que usaré cuando llegue la oportunidad. Mi alfabeto es egocéntrico, eso sí: hablo de mí misma, invento sobre mí misma, me disfrazo y me maquillo yo misma. Yo, que nunca soporté la autoficción. Mientras ellos hablaron de personas famosas o acontecimientos históricos, filosofía o política, yo me dedico a redecorarme. No tengo la humildad que se requiere para hacerme a un lado. Como aquella vedette antiquísima de la televisión venezolana llamada -precisamente- "La Polaca", me contoneo en el medio del escenario. No en vano pasé horas frente al espejo cuando era niña tratando de emularla. (5 de octubre de 2011)

No es de extrañar, entonces, que este sujeto disperso se vea impedido para ejercer cabalmente el papel de ciudadano. La participación política exige, casi como condición de posibilidad, la unidad identitaria. Es por eso que desde una identidad dispersa toda participación o demanda política se disuelve o 
se confunde. Incluso cuando hay una expresa voluntad de participar, de estar ahí, de enseñarles a los propios hijos una lección política, el impulso hacia la participación pública no parece tener otro destino que una forma compleja de solipsismo, como se evidencia en la entrada titulada " $\mathrm{R}$ de revolución":

Grito mal todas las consignas, aunque me las expliquen, me las hagan repetir, me las enseñen escritas en letras hebreas, me las pasen a letras latinas. En medio de la emoción primitiva de por fin estar de acuerdo con los otros, la lengua se me distiende y no pronuncio las "ts" ni las "dz". Así que voy diciendo cualquier cosa. Voy en mi revolución personal. Mi pequeña alegría: no estoy sola aunque mis consignas sean diferentes. Por fin veo gente que hace a un lado el miedo, la religión, el fanatismo, la cuadradés, la miopía y se echa a la calle a pedir justicia social. A cuenta de una guerra eterna, este país ha escaldado a sus habitantes. Los de allá son bombardeados con misiles reales, los de acá con miedos, impuestos, usura, trampa. (27 de octubre de 2011)

Pero tal vez de lo que se trata es, precisamente, de mostrar las diferencias y los malentendidos que perpetúan la distancia entre sujetos que convergen sin coincidir, porque vienen de mundos demasiado diversos. Es en ese encuentro con la identidad del otro cuando la propia identidad parece amalgamarse o, al menos, perder en algo la dispersión del que se disuelve en un mundo globalizado. Ante un sujeto radicalmente distinto, como se cuenta en "W de WiFi", la narradora se detiene y se abisma. Se trata de un hombre "que no sabe leer", que "apenas conoce la lengua en la que habita". El hombre se sube a un autobús y con mucha dificultad logra que el chofer entienda adónde se dirige. El autobús tiene un letrero que el hombre no lee, que no podría entender aunque leyera: "Este autobús tiene WiFi" (11 de abril de 2012).

Esta escena de desencuentros muestra que el desterrado vive en medio del contraste entre dos mundos, el mundo del ensimismamiento cultural de sujetos no globalizados y el mundo de la conectividad sin límites en el que es posible estar a la vez "en un autobús que recorre vías frente al mar, caminos entre pinos y cipreses, carreteras bordeando sembradíos al sur de Israel" y "en una conversación en Caracas" o leyendo "una información sobre Calcuta". Frente a "este señor vestido como un rey africano" la narradora admite: "La que no sabe de realidades paralelas soy yo"; y en esa aceptación el yo se reconcentra y se aglutina, siguiendo una de las leyes más tercas de la formación de discursos identitarios, aquella que sostiene que solo es posible descubrir la identidad cuando se la contrasta con una radical diferencia. 
El recorrido que va de la dispersión a la reconfiguración identitaria no es, por supuesto, un proceso lineal. El movimiento de las voces que narran el desarraigo en los blogs de venezolanas que viven en el extranjero es un movimiento pendular, en el mejor de los casos, circular casi siempre. Porque no parece haber en estas voces una voluntad de regresar a las narrativas lineales en las que el sujeto migrante alcanza un estado específico en la construcción de sí mismo -como en las ficciones de arraigo tradicionales- para asentar su identidad en una tierra, aunque esta sea extranjera. El arraigo se construye aquí en un lugar híbrido, a medias entre la memoria y el olvido, el espacio real y el virtual. $Y$ es en ese entrelugar donde la pertenencia se reconfigura para producir un nuevo modo de imaginar el territorio del origen y poner a funcionar otras formas de representación de la pertenencia.

\section{Identidades del entrelugar}

El arraigo se vuelve una premisa inestable en los textos de estas mujeres desterradas. Lo público y lo íntimo colapsan en un entrelugar que cobra una densidad no transitoria, para volverse un estado del ser, como sostiene Brian Massumi $^{7}$. En ese entrelugar que es el destierro, las voces de estas autoras reclaman un reconocimiento de otro tipo. Porque hablan en un tono que no responde a los gestos grandilocuentes de los intelectuales orgánicos -de la izquierda o la derecha; del Gobierno o la oposición- sino que se expresa en lo menudo, en lo cotidiano, para enfatizar que su discurso se genera desde una política del afecto. Es en estos territorios afectivos donde adquieren legitimidad los textos que hemos comentado.

Un reconocimiento que es posible observar en el intercambio que se produce entre las autoras y su público, cuando los lectores dejan comentarios a los distintos posts. La respuesta a estos comentarios es siempre alentadora, inclusiva, sentimental. Y este intercambio de afectos modifica la relación autor-lector y coloca al intelectual que elabora el discurso identitario en un plano de igualdad, que es una de las marcas de los intercambios simbólicos caracterizados por Ludmer como íntimopúblico. Un lugar en el que los discursos circulan como si la funciónautor se hubiese desvanecido y solo quedara en pie un diálogo abierto, anónimo,

7 Brian Massumi se pregunta: "What would it mean to give a logical consistency to the inbetween? It would mean realigning with a logic of relation. For the in-between, as such, is not a middling being but rather the being of the middle -the being of a relation". (“QQué significaría otorgar consistencia lógica al entrelugar? Significaría realinearlo con una lógica relacional. Porque el entrelugar, como tal, no es un ser medianero, sino un ser del medio, el producto de una relación") (énfasis en el original). 
continuo. Un diálogo que va construyendo, junto con otros desterrados, la "intimidad diaspórica" de la que habla Svetlana Boym, que no promete una "fusión emocional no mediada, sino solamente un afecto precario", que sin embargo es suficiente, en condición de destierro, para crear un sentimiento de comunidad construido sobre la base de una "nostalgia compartida sin pertenencia" (252; la traducción es mía) $)^{8}$.

Y es desde esas sensibilidades diaspóricas que se fragua una relación distinta con el lugar de origen que, aunque pasa por la visita al repertorio de los discursos de la nacionalidad -el acento, las comidas, los mapas del territorio de origen-, se empeña ante todo en construir nuevos relatos identitarios en los que tenga cabida, junto con la distancia y la nostalgia, otro modo de participación ciudadana. La posibilidad de un viaje de regreso, aunque solo sea simbólico, que permita la presencia del desterrado en el debate local. Pero se trata de una participación sesgada, debido a que en la agenda del intelectual desterrado el enigma de la nación ya no está en el centro y la comprensión del presente se construye desde un horizonte globalizado.

Porque, como sostiene Julio Ramos, "se trata de un modo de concebir la identidad que se escabulle de las redes topográficas y las categorías duras de la territorialidad y su metaforización telúrica" (186), dejando en pie, a cambio, una serie fragmentaria que pone en evidencia la escenografía de la identidad, como hemos visto en los textos de Leila Macor; al menos hasta el momento del encuentro fortuito con un otro absoluto, como sucede en uno de los escritos de Liliana Lara. Y es por eso que en estas autoficciones el límite entre el afuera y el adentro a ratos se borra, como se puede leer en algunas de las crónicas de Mirtha Rivero. Porque la frontera se desplaza de la geografía al territorio de los afectos. Y en ese espacio en el que solo reinan la memoria y el olvido, la nación no es más que un repertorio de ficciones entre los muchos que configuran las identidades diaspóricas.

8 Boym sostiene que: "Diasporic intimacy does not promise an unmediated emotional fusion, but only a precarious affection -no less deep, yet aware of its transience. In contrast to the utopian images of intimacy as transparency, authenticity and ultimate belonging, diasporic intimacy is dystopic by definition; it is rooted in the suspicion of a single home, in shared longing without belonging" ("La intimidad diaspórica no promete una fusión emocional no mediada, sino solamente un afecto precario -no menos profundo y sin embargo consciente de su transitoriedad-. En contraste con las imágenes utópicas de la intimidad como transparencia, autenticidad y pertenencia definitiva, la intimidad diaspórica es distópica por definición; se arraiga en la sospecha de un solo lugar de origen, en un anhelo compartido sin pertenencia.") (252). 


\section{Obras citadas}

Boym, Svetlana. The Future of Nostalgia. Nueva York: Basic Books, 2001.

González Echevarría, Roberto. Myth and Archive. A Theory of Latin American

Narrative. Durham; Londres: Duke University Press, 1998.

González Stephan, Beatriz et al, comps. Esplendores y miserias del siglo XIX. Cultura y sociedad en América Latina. Caracas: Monte Ávila; Equinoccio, 1995.

Lara, Liliana. Memorias de la mamacita. Blogspot. Web. 2012. $<$ memoriasdelamamacita.blogspot.com>.

Ludmer, Josefina. "Tretas del débil". La sartén por el mango: encuentro de escritoras latinoamericanas. Ed. Eliana Ortega. Río Piedras: Huracán, 1983. 47-54.

- Aquí América Latina. Una especulación. Buenos Aires: Eterna Cadencia, 2010.

Macor, Leila. "El blog incontrolable". Observa Ciudadano. El Observador. 13 de julio de 2008. Web. 25 de junio de 2012. <www.observa.com.uy>.

— "El presidente humorista". Observa Ciudadano. El Observador. 1. ${ }^{\circ} \mathrm{de}$ diciembre de 2008. Web. 25 de junio de 2012. <www.observa.com.uy>.

- Escribir para qué. Blogspot. Web. 2012. <escribirparaque.blogspot.com>.

Massumi, Brian. Parables for the Virtual. Movement, Affect, Sensation. Durham: Duke University Press, 2002.

Pavel, Thomas. "Exile as Romance and as Tragedy". Exile and Creativity. Signposts, Travelers, Outsiders, Backward Glances. Ed. Susan Rubin Suleiman. Durham; Londres: Duke University Press, 1998. 25-36.

Rama, Ángel. La ciudad letrada. Hanover: Ediciones del Norte, 1984.

Ramos, Julio. "Migratorias". Paradojas de la letra. Caracas: eXcultura, 1996. 177-186.

Rivero, Mirtha. Prodavinci. Actualidad.

Web. 2012. <http://prodavinci.com/author/mirtha/>.

Said, Edward. Reflections on Exile: And Other Literary and

Cultural Essays. Londres: Granta, 2001.

Sibila, Paula. La intimidad como espectáculo. Buenos

Aires: Fondo de Cultura Económica, 2009.

Silva Beauregard, Paulette. "Novela e imaginación pública en la Venezuela actual. El regreso de viejos fantasmas (1)". Espéculo XV. 48 (2011) Web. 28 de junio 2012. 